\title{
Automatic Power Factor Correction Using a Harmonic-Suppressed TCR Equipped with a New Adaptive Current Controller
}

\author{
Abdulkareem Mokif Obais* and Jagadeesh Pasupuleti ${ }^{\dagger}$ \\ *Department of Electrical Engineering, Babylon University, Babylon, Iraq \\ ${ }^{\dagger}$ Department of Electrical Power Engineering, Universiti Tenaga Nasional, Selangor, Malaysia
}

\begin{abstract}
In this paper, a new continuously and linearly controlled capacitive static VAR compensator is proposed for the automatic power factor correction of inductive single phase loads in $220 \mathrm{~V} 50 \mathrm{~Hz}$ power system networks. The compensator is constructed of a harmonic-suppressed TCR equipped with a new adaptive current controller. The harmonic-suppressed TCR is a new configuration that includes a thyristor controlled reactor (TCR) shunted by a passive third harmonic filter. In addition, the parallel configuration is connected to an AC source via a series first harmonic filter. The harmonic-suppressed TCR is designed so that negligible harmonic current components are injected into the $\mathrm{AC}$ source. The compensator is equipped with a new adaptive closed loop current controller, which responds linearly to reactive current demands. The no load operating losses of this compensator are negligible when compared to its capacitive reactive current rating. The proposed system is validated on PSpice which is very close in terms of performance to real hardware.
\end{abstract}

Key words: Controlled reactor, Power factor correction, Power quality, Reactive power control, Static VAR compensators

\section{INTRODUCTION}

Poor power factor is a challenging issue facing power quality achievement. It causes extra losses in transmission systems and power generation stations. In addition, it may restrict the transmission capability of transmission systems. Therefore, power factor correction is an effective remedy for this issue. The benefits of power factor correction include energy savings, transmission loss reductions, and the feasibility of operating transmission lines closer to their thermal limits. Effective tools used to achieve power factor correction include static VAR compensators such as fixed capacitor thyristor controlled reactors, thyristor switched capacitors (TSC), static synchronous compensators (statcom), and power converter based static VAR compensators [1]-[8]. The traditional thyristor controller reactor (TCR) is simply a reactor connected in series to two anti-parallel thyristors where the series combination is supplied by the phase or line

Manuscript received May 5, 2013; accepted Mar. 25, 2014

Recommended for publication by Associate Editor Kyeon Hur.

${ }^{\dagger}$ Corresponding Author: karimobais@yahoo.com

Tel: +60-133081625, Universiti Tenaga Nasional

*Dept. of Electrical Eng., Babylon University, Babylon, Iraq to line voltage of the $\mathrm{AC}$ power system network. It is controlled continuously by the symmetric firing angles of its thyristors. It releases significant amounts of odd current harmonics. As a result, it requires the installation of harmonic filters at its location [9]-[11]. TCRs are considered to be an important application of what is known as Flexible Alternative of Current Transmission Systems (FACTS) devices, which represent the recent application of power electronics in transmission systems [12]-[16]. FACTS devices are designed to satisfy the real time demands of power systems. A TSC is constructed of a capacitor connected in series to two anti-parallel thyristors where the series combination is supplied by the phase or line to line voltage of an AC source. A compensator constructed of several TSCs is characterized by a stepwise capacitive reactive power response [17]-[19]. In the design of TCRs, and TSC based static VAR compensators, naturally commutated thyristors are usually employed. These kinds of compensators are commonly referred to as traditional static VAR compensators.

Power converter based static VAR compensators are constructed of either voltage source inverter (VSI) or current 
source inverter (CSI) [20]-[22]. They are designed to exchange real power and reactive power with the AC networks through certain impedances. They can be adjusted to exchange reactive power and active power with the AC power system networks by changing the phases of the triggering signals of their solid-state switching devices. These kinds of compensators are usually supported by energy storage devices in order to stabilize their DC voltages. A statcom is an application based on the power conversion principles. It is either a voltage source inverter shunted by a DC capacitor [23] or a current source inverter shunted by a DC reactor [24]. Both categories can exchange capacitive or inductive reactive power with the AC network through, to some extent, small series impedances (usually small reactors). Statcoms can be used to control both real power and reactive power. They are built with different topologies in order to satisfy the requirements of being employed in applications requiring higher voltage and current ratings in addition to treating the current harmonics associated with their compensating currents [25]-[27]. Static VAR compensators built on the basis of power conversion are usually denoted by advanced static VAR compensators.

In this paper, a modified harmonic-free configuration constructed with a TCR and two passive circuits is presented as a reliable replacement for a fixed capacitor thyristor controlled reactor shunted by high power harmonic filters. This configuration represents a continuously and linearly controlled capacitive static VAR compensator. The capacitive current of this compensator is controlled by a new adaptive closed loop current controller, which forces the compensator to respond linearly to the reactive current demand.

\section{SCHEMATIC DESIGN OF THE PROPOSED AUTOMATIC POWER FACTOR CORRECTION SYSTEM}

The layout of the proposed system is shown in Fig. 1. The compensator power circuit is built with a traditional TCR and two filtering circuits. $L_{X}$ and $R_{X}$ are the self-inductance and resistance of the TCR reactor. The first filtering circuit is represented by the series circuit $C_{F 1} L_{F 1} R_{F 1}$, which is tuned at the AC source fundamental angular frequency $\omega . R_{F 1}$ is the self-resistance of $L_{F 1}$. The second circuit is formed with $C_{F 2} L_{F 2} R_{F 2}$ and it is tuned at $3 \omega . R_{F 2}$ is the self-resistance of $L_{F 2}$.

The actual waveform of the TCR current $i_{X}$ at a certain firing angle $\alpha$ is shown in Fig. 2. In this figure, $v_{X}$ represents the AC voltage exerted across the TCR terminals, and $\alpha$ is the angle measured from the positive peak point of $v_{X}$ to its next negative slope zero-crossing point. This angle varies in the range of $0 \leq \alpha \leq \pi / 2$. The absolute fundamental and nth harmonic current components of the TCR current are given by [1]:

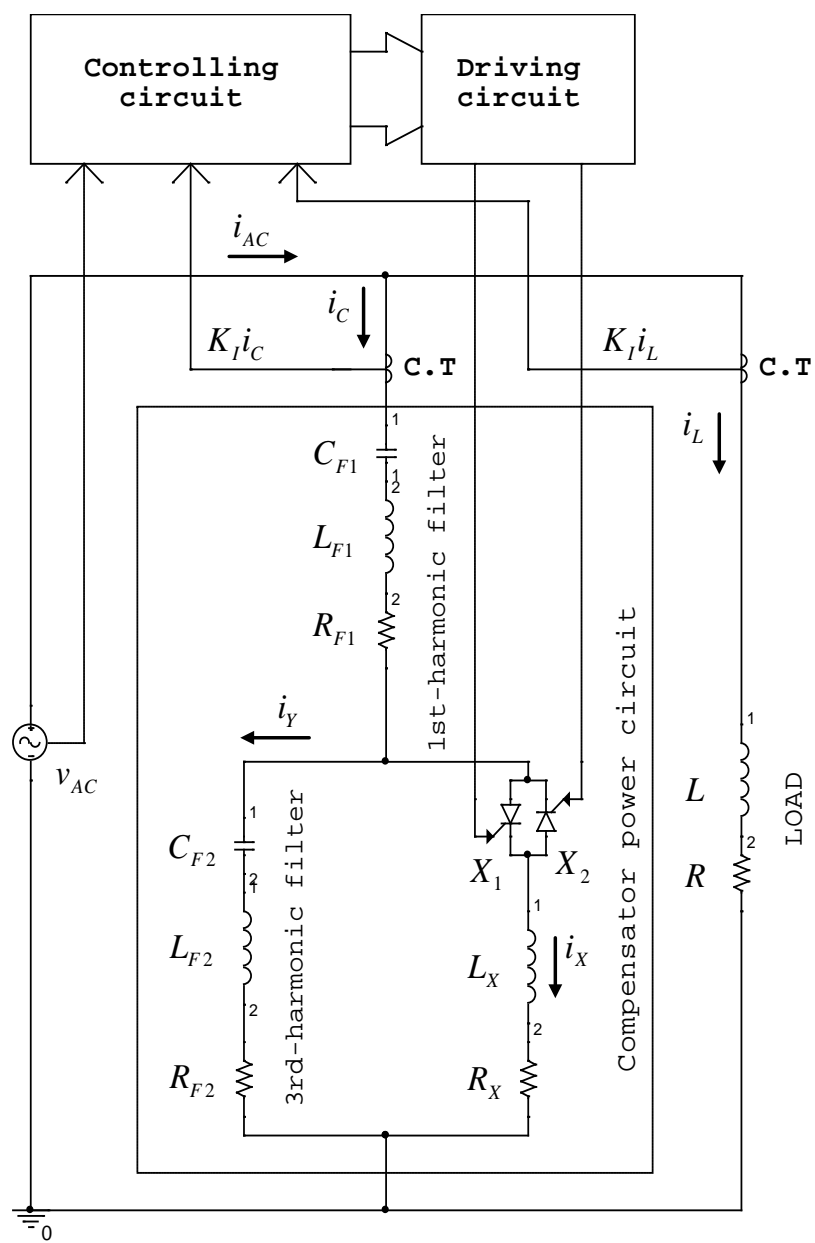

Fig. 1. Layout of the proposed automatic power factor correction system.

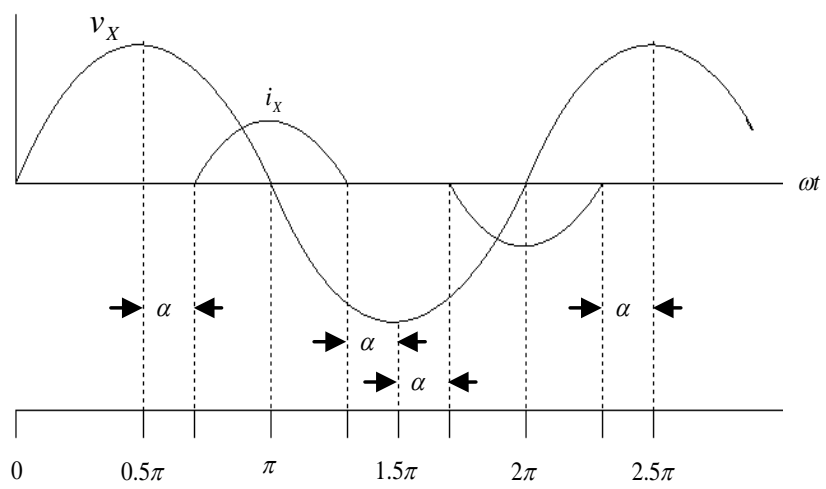

Fig. 2. The TCR current waveform.

$$
\begin{gathered}
I_{1}=\frac{V_{m}}{\omega L_{X}}\left(1-\frac{2 \alpha}{\pi}-\frac{\sin 2 \alpha}{\pi}\right) \\
I_{n}=\frac{4 V_{m}}{\pi \omega L_{X}}\left(\frac{\sin \alpha \cos (n \alpha)-n \cos \alpha \sin (n \alpha)}{n\left(n^{2}-1\right)}\right)
\end{gathered}
$$

Where, $V_{\mathrm{m}}$ is the amplitude of $v_{X}$, and $n$ is a positive odd integer greater than unity. 
Since the first and second filtering circuits are tuned at $\omega$ and $3 \omega$, respectively, the following can be written:

$$
\begin{gathered}
X_{F 1}=\omega L_{F 1}=\frac{1}{\omega C_{F 1}} \\
X_{F 2}=3 \omega L_{F 2}=\frac{1}{3 \omega C_{F 2}}
\end{gathered}
$$

Where, $X_{F 1}$ and $X_{F 2}$ are the characteristic impedances of the first and second filtering impedances, respectively, at the corresponding resonance frequencies of $\omega$ and $3 \omega$. At the fundamental angular frequency $\omega$ of the $\mathrm{AC}$ source, these impedances can be expressed as follows:

$$
\begin{gathered}
Z_{F 1}(\omega)=\dot{\omega} L_{F 1}+\frac{1}{j \omega C_{F 1}}+R_{F 1}=R_{F 1} \\
Z_{F 2}(\omega)=\dot{\omega} L_{F 2}+\frac{1}{j \omega C_{F 2}}+R_{F 2} \cong-j\left(\frac{8}{3}\right) X_{F 2}
\end{gathered}
$$

Where, $Z_{F 1}(\omega)$ and $Z_{F 2}(\omega)$ are the impedances of the first and second filtering circuits at the AC source fundamental. In Equation (6), the self-resistance $R_{F 2}$ is neglected because it is very small when compared to the imaginary part of $Z_{F 2}(\omega)$.

The second filtering circuit and the TCR circuit are designed so that the parallel combination draws zero reactive current during zero reactive current demand. This implies that:

$$
\frac{1}{Z_{F 2}(\omega)}+\frac{1}{j \omega L_{X}+R_{X}}=0
$$

Since $R_{X}$ is negligible when compared to $\omega L_{X}$, Equation (7) can be closely approximated to:

$$
X_{F 2}=\frac{3}{8} \omega L_{X}
$$

At the nth harmonic frequency, the impedances of the first and second filtering circuits can be expressed as follows:

$$
\begin{gathered}
Z_{F 1}(n \omega)=j \omega L_{F 1}+\left(\frac{1}{j \omega C_{F 1}}\right)=\mathrm{j} X_{F 1}\left(\frac{n^{2}-1}{n}\right) \\
Z_{F 2}(n \omega)=j \omega L_{F 2}+\frac{1}{j \omega C_{F 2}}=\mathrm{j} X_{F 2}\left(\frac{n^{2}-9}{3 n}\right)
\end{gathered}
$$

To make this compensator suppress all of the current harmonics with orders higher than the $9^{\text {th }}$ harmonic, the nth harmonic current component flowing through the AC source side should be at least one tenth the component released by the TCR. This implies that:

$$
Z_{F 2}(n \omega)=\left(\frac{1}{9}\right) Z_{F 1}(n \omega), n>9
$$

Substituting Equation (9) and (10) into (11) gives the following closely approximated equation:

$$
X_{F 1=} 3 X_{F 2}
$$

Equations (8) and (12) are the basic design equations of the proposed harmonic-suppressed TCR. Using these equations, the passive elements of the harmonic-suppressed TCR can be expressed in terms of its reactor inductance as follows:

$$
\begin{aligned}
L_{F 1} & =\frac{9}{8} L_{X} \\
L_{F 2} & =\frac{1}{8} L_{X} \\
C_{F 1} & =\frac{8}{9 \omega^{2} L_{X}} \\
C_{F 2} & =\frac{9}{8 \omega^{2} L_{X}}
\end{aligned}
$$

\section{SChematic Design OF THE NeW AdAPtive CONTROLLER}

The controlling scheme of the proposed compensator is shown in Fig. 3. The inputs to this controller are the instantaneous AC source voltage $v_{A C}$, a voltage signal proportional to the instantaneous compensator current $K_{I} i_{C}$, and a voltage signal proportional to the instantaneous load current $K_{I} i_{L}$. Where, $K_{I}$ is a constant depending on the current transformer turn ratio and the parameters of its circuitry. The voltage $v_{A C}$ is exerted to a step-down voltage transformer in order to produce the analogue voltage $K_{V} v_{A C}$. Where, the $K_{V}$ constant stands for the primary to secondary turn ratio of the voltage transformer. The analogue voltage $K_{V} v_{A C}$ is zero-crossed and then delayed by $5 \mathrm{~ms}$ to produce the voltage waveforms $v_{S 1}$ and $v_{S 2}$. A third voltage waveform $v_{S 3}$ is produced through the XOR operation of $v_{S 1}$ and $v_{S 2}$. The waveform $v_{S 3}$ is exerted on a saw-tooth generator to produce the signal $v_{S T}$ which has an amplitude of $4 \mathrm{~V}$ and runs at a frequency of $2 f$. Where, $f$ is the frequency of the AC source $(f=\omega / 2 \pi)$.

The voltage waveform $v_{S T}$ is subtracted from a DC voltage of $4 \mathrm{~V}$ to produce the reference voltage waveform $v_{R E F}$ which is used together with the output of the current controller to determine the TCR firing angle $\alpha$. The inputs of the current controller are the analogue voltages $K_{I} i_{C}$ and $K_{I} i_{L}$. In this controller, a closed loop strategy is adopted so that its output $v_{C X}$ settles when the reactive current components of the inductive load and the compensator current cancel each other out. The analogue signal controlling the firing angle of the TCR is obtained by comparing the output of the current controller $v_{C X}$ with the reference voltage waveform $v_{R E F}$. The latter waveform varies in the range of 0 to $+4 \mathrm{~V}$. The waveforms of the new adaptive controlling scheme are shown in Fig. 4. By examining this figure, it can be seen that the TCR firing angle can be related to the voltage $v_{C X}$ as follows:

$$
\propto=\frac{\pi}{2}\left(1-\frac{v_{C X}}{4}\right)
$$

The instantaneous fundamental current of the TCR $\left(i_{X I}\right)$ can 
expressed as follows:

$$
i_{X 1}=\frac{V_{m}}{\omega L_{X}}\left(1-\frac{2 \alpha}{\pi}-\frac{\sin 2 \alpha}{\pi}\right) \dot{s i n}\left(\omega t-\frac{\pi}{2}\right)
$$

The instantaneous fundamental current of the third harmonic filter $\left(i_{Y I}\right)$ can expressed as follows:

$$
i_{Y 1}=\frac{3 V_{m}}{8 \omega L_{F 2}} \dot{s i n}\left(\omega t+\frac{\pi}{2}\right)
$$

Since this compensator is designed so that negligible harmonic current components are permitted to flow into the AC source side, its instantaneous current $\left(i_{C}\right)$ contains only the fundamental current components of the third harmonic filter and the TCR. Consequently, $i_{C}$ can determined as follows:

$$
i_{C}=i_{X 1}+i_{Y 1}
$$

Substituting Equations (18), (19), and (8) into (20) gives:

$$
i_{C}=\frac{V_{m}}{\omega L_{X}}\left(\frac{2 \alpha}{\pi}+\frac{\sin 2 \alpha}{\pi}\right) \dot{s i n}\left(\omega t+\frac{\pi}{2}\right)
$$

Substituting Equation (17) into (21) gives:

$$
i_{C}=\frac{V_{m}}{\omega L_{X}}\left(\left(1-\frac{v_{C X}}{4}\right)+\frac{\sin \pi\left(1-\frac{v_{C X}}{4}\right)}{\pi}\right) \dot{s i n}\left(\omega t+\frac{\pi}{2}\right)
$$

Equation (22) indicates that the compensator current is purely capacitive and can be directly controlled by the voltage $v_{C X}$. If $v_{C X}$ is zero, then the compensator will generate its maximum reactive current. On the other hand, its current will be zero if $v_{C X}$ is $+4 \mathrm{~V}$. The instantaneous current of the inductive load can be defined by:

$$
i_{L}=I_{L m} \dot{s i n}(\omega t-\varphi)
$$

Where, $I_{L m}$ and $\varphi$ are the amplitude and power factor angle of the inductive load, respectively. The automatic power factor correction system is designed so that the compensator current cancels the reactive current component of the inductive load. Consequently, the following can be written:

$$
\frac{V_{m}}{\omega L_{X}}\left(\left(1-\frac{v_{C X}}{4}\right)+\frac{\sin \pi\left(1-\frac{v_{C X}}{4}\right)}{\pi}\right)-I_{L m} \dot{s i n}(\varphi)=0
$$

Equation (24) is directly governed by $v_{C X}$. A closed loop control strategy is adopted in this paper to make Equation (24) settle to zero within a short time.

The new adaptive current controller of the proposed compensator is shown in Fig. 5. The actual current of the harmonic-suppressed TCR $i_{C}$ is detected by a current transformer and converted to the analogue voltage $K_{I} i_{C}$. Where, $K_{I}$ is a constant depending on the current transformer turn ratio and the parameters of its circuitry. The load current is detected
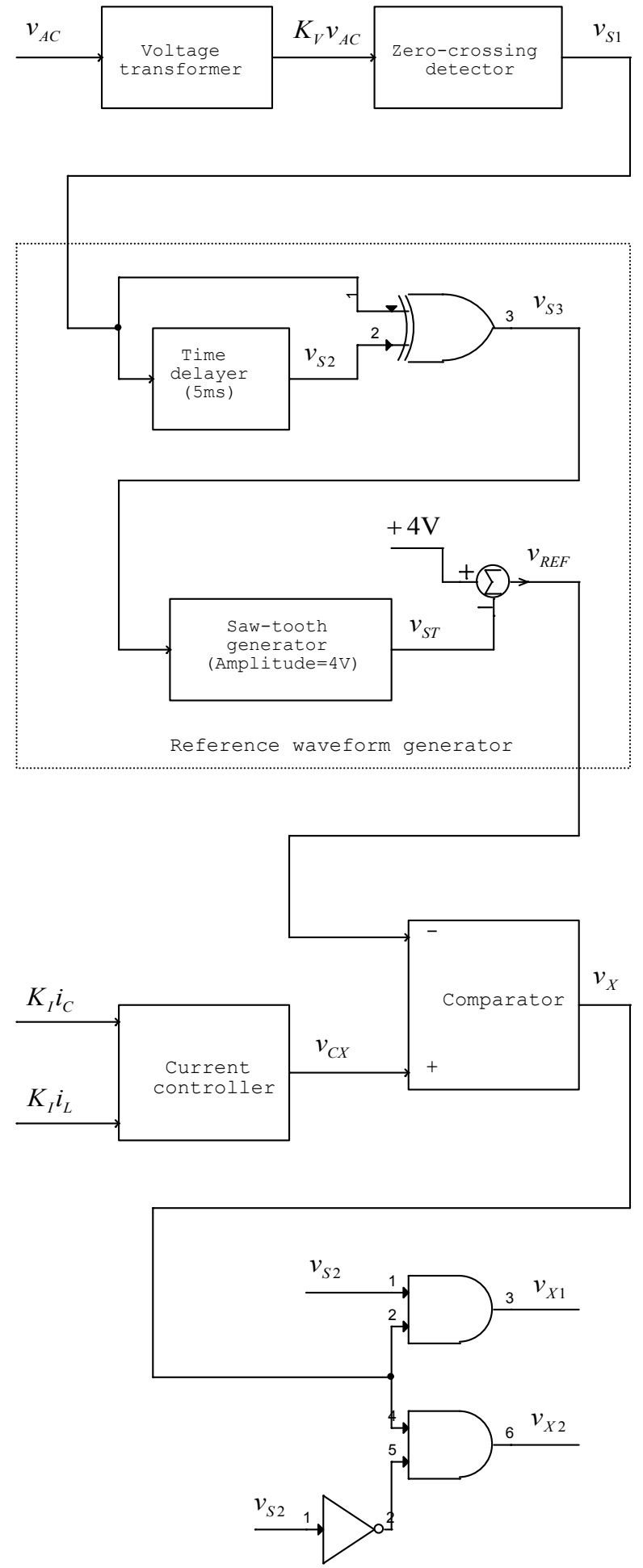

Fig. 3. The new adaptive controlling scheme.

by a similar current transformer and converted to the analogue voltage $K_{I} i_{L}$. The analogue voltage signal $K_{I} i_{C}$ is sampled and held at $\omega t=2 k \pi$ and $\omega t=(1+k) \pi$ in order to detect $K_{I} I_{C m}$ and $-K_{I} I_{C m}$. Where, $k=0,1,2,3, \ldots$ and $I_{C \mathrm{~m}}$ is the actual amplitude of the compensator current $i_{C}$. The two sampled signals are treated through a difference amplifier for obtaining the mean of $K_{I} I_{C m}$. 


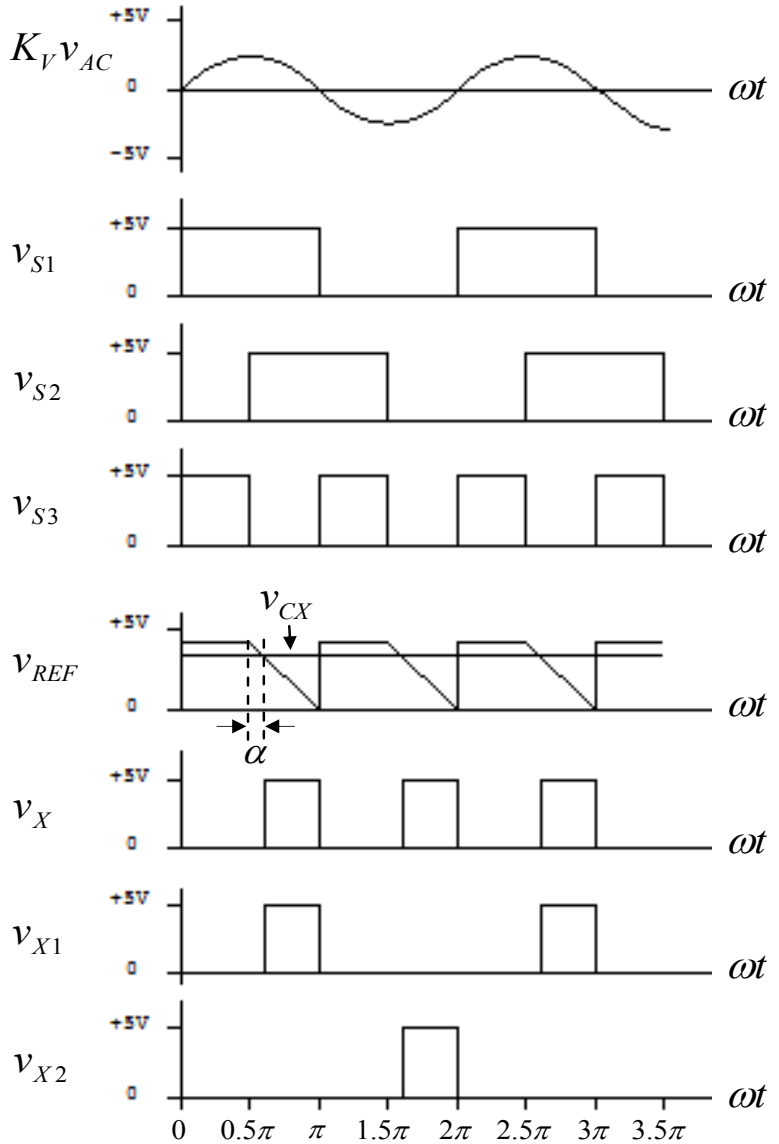

Fig. 4. The voltage waveforms of the new adaptive controller of the proposed compensator.

The latter signal is proportional to the compensator capacitive reactive current. The analogue voltage signal $K_{I} i_{L}$ is sampled and held at $\omega t=2 k \pi$ for obtaining the analogue voltage signal $K_{I} I_{L m} \sin (\varphi)$, which is proportional to the inductive load reactive current component.

The voltage across capacitor $C_{X}$ represents the controller output voltage $v_{C X}$. This voltage directly controls the triggering circuits of the thyristors employed in the compensator design. If the error signal becomes zero, then the charging and discharging processes will cease and the capacitor will sustain its final voltage as long as the error signal is not effective. Therefore, the steady state operation is reached when the error signal continues having zero values.

The TCR controlling signal $v_{X}$ is produced by comparing $v_{C x}$ with $v_{R E F}$. The voltage signal $v_{X}$ is logically multiplied by $v_{S 2}$ and its complement to obtain the TCR thyristor triggering signals $v_{X I}$ and $v_{X 2}$, as shown in Fig. 4. The triggering signals $v_{X 1}$ and $v_{X 2}$ can be defined by:

$$
\begin{aligned}
& v_{X 1}=v_{X} v_{S 2} \\
& v_{X 2}=v_{X} \overline{v_{S 2}}
\end{aligned}
$$

A validation system for the proposed automatic power factor correction system is designed on Pspice, as shown in Fig. 6.

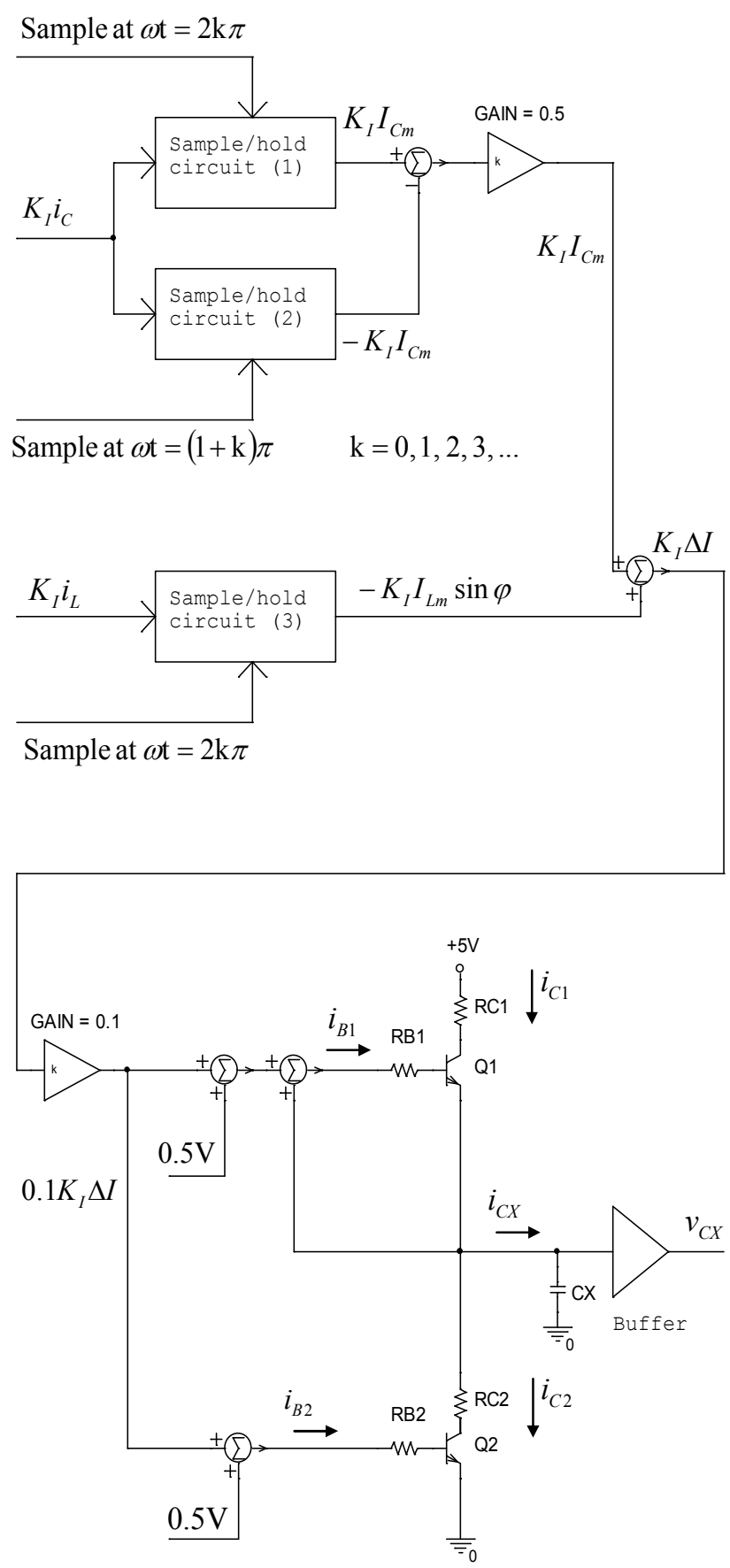

Fig. 5. The new adaptive current controller of proposed compensator.

The system is designed so that it has a reactive current rating of $110 \mathrm{~A}$ (peak) in a $220 \mathrm{~V} 50 \mathrm{~Hz}$ power system network.

The reference waveform generator is shown in Fig. 7. This generator produces the voltage signal $v_{R E F}$ illustrated in Fig. 4.

A circuit diagram of the new adaptive current controller is shown in Fig. 8. This figure represents a circuit diagram that stands for the schematic design shown in Fig. 5. 


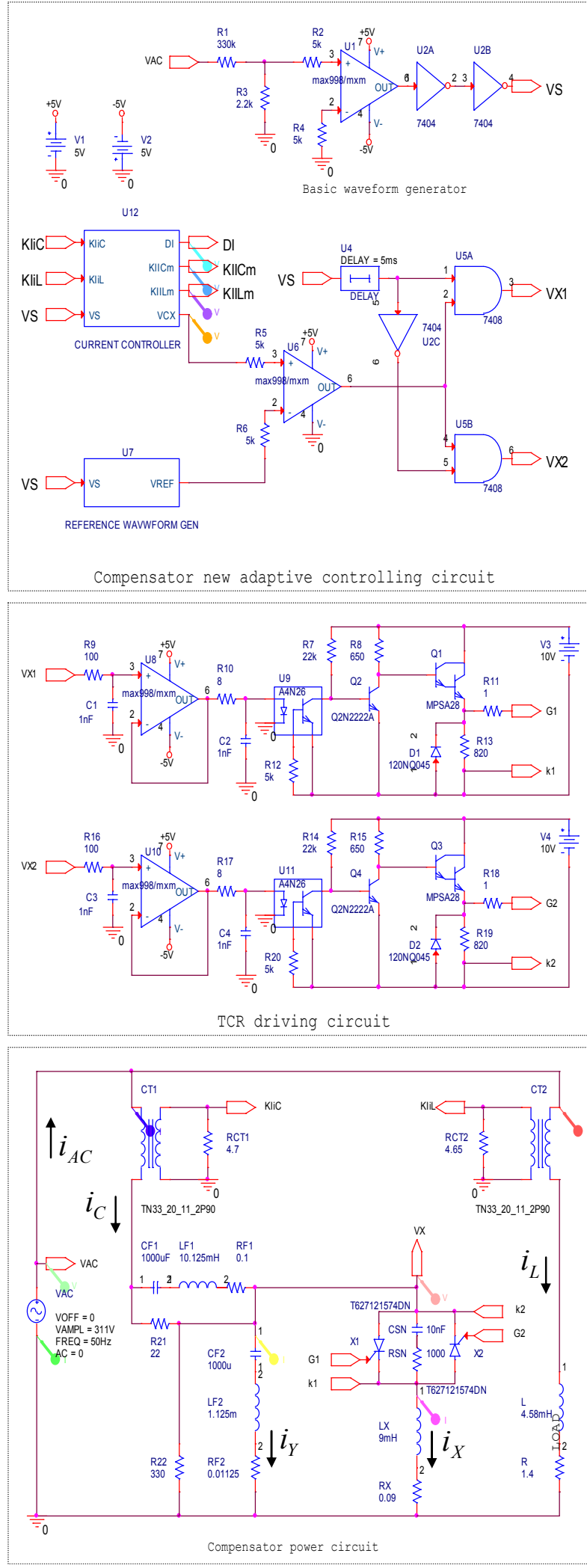

Fig. 6. The PSpice validation system of proposed automatic power factor correction system.

According to the specified reactive current rating, the inductance of the TCR reactor $L_{X}$ is calculated to be

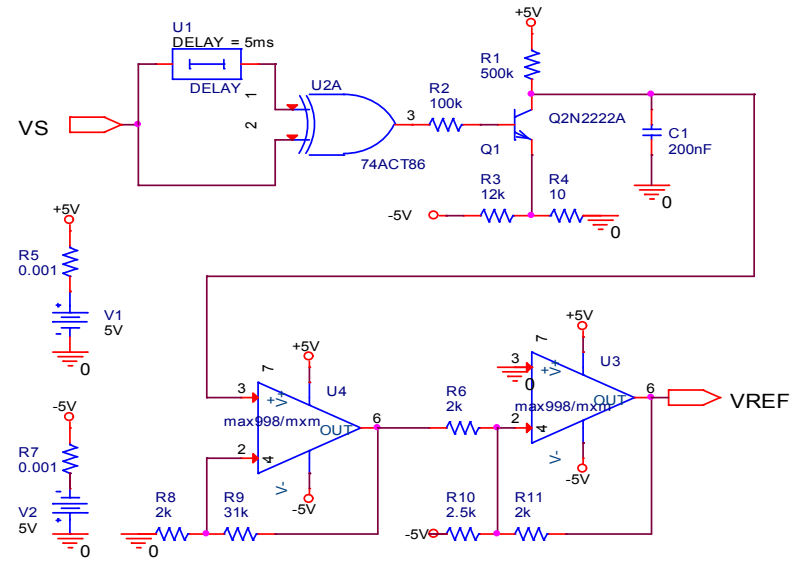

Fig. 7. The reference waveform generator.

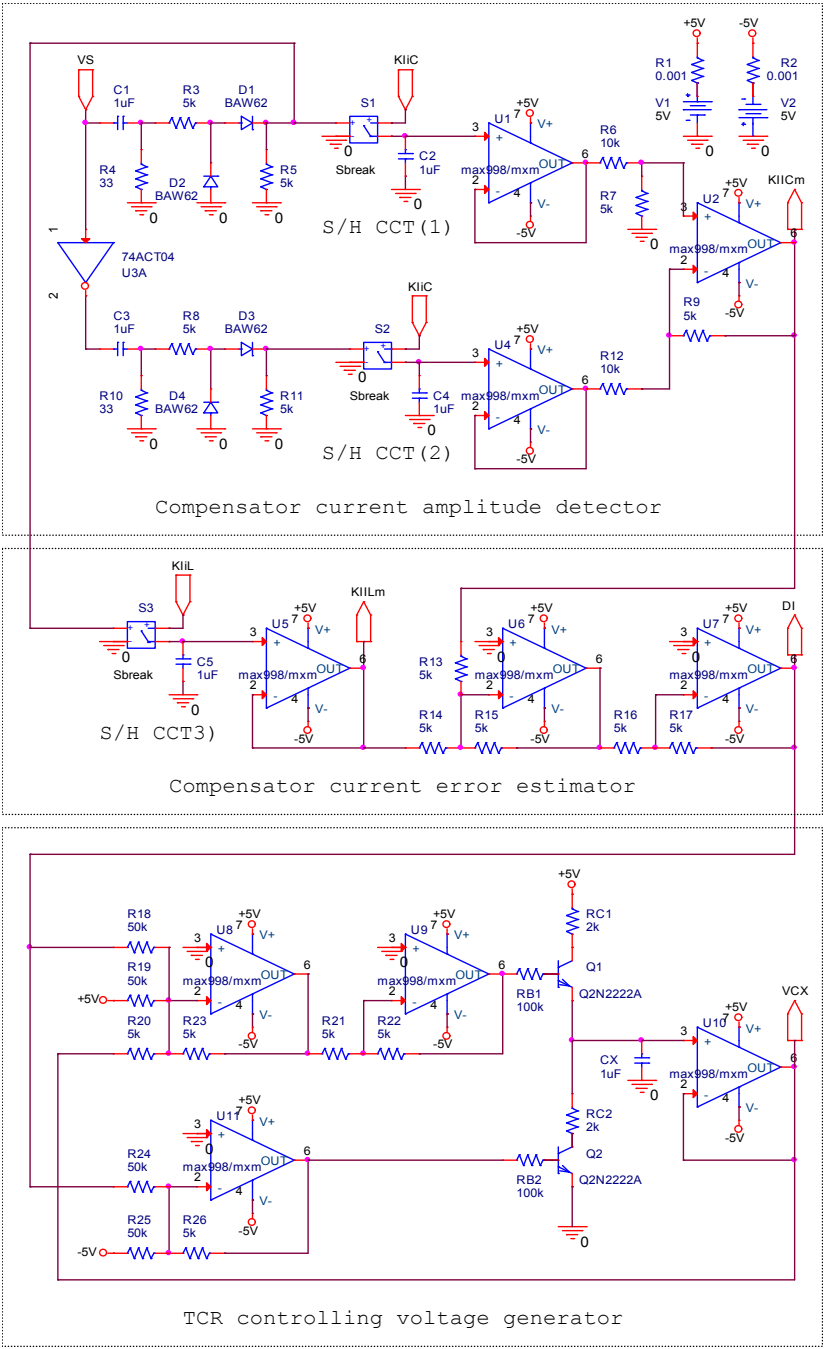

Fig. 8. The circuit diagram of the adaptive current controller.

$(311 \mathrm{~V} / 110 \mathrm{~A})=9 \mathrm{mH} .311 \mathrm{~V}$ stands for the rms value of $220 \mathrm{~V}$. According to this value of $L_{X}$ and using the design Equations (13) to (16), the following design values are obtained: $L_{F 1}=10.125 \mathrm{mH}, C_{F I}=1000 \mu \mathrm{F}, L_{F 2}=1.125 \mathrm{mH}$, and $C_{F 2}=1000 \mu \mathrm{F}$. 
The self-resistances of the reactors are chosen so that the resistance to inductance ratio is $10 \Omega / \mathrm{H}$ in order to reduce their losses and to make them behave, to some extent, as pure reactances.

Two identical current transformers are used in this design. The primary to secondary ratio of each transformer is $1: 100$. The thyristors used are T627121574DNs. These thyristors have continuous voltage and current ratings of $2200 \mathrm{~V}$ and $300 \mathrm{~A}$, respectively.

The npn transistors used in the new adaptive controller design are Q2N2222As. These transistors have continuous voltage and current ratings of $75 \mathrm{~V}$ and $800 \mathrm{~mA}$, respectively. Their forward current gain $\beta$ is 256 .

\section{RESUlTS AND DisCUSSION}

The automatic power factor correction system depicted in Fig. 6 was tested in PSpice at rated load currents with different lagging power factors. The PSpice tests involve the transient and steady state performance of the compensation system. The transient performance started from the first plug in instant of the compensator to the AC power system network and ended once the compensator current was completely settled. The steady state performance started from the instant at which the compensator current was completely settled. Therefore, it is appropriate to reveal the transient and steady state performance results together to show the instants at which the steady state performance started. Then the steady state performance results are revealed to demonstrate the potency of the compensator in power factor correction and harmonic cancellation.

\section{A. Transient and Steady State Performance}

The automatic power factor correction system in this paper is proposed to correct to unity the power factor of a single-phase inductive load in a $220 \mathrm{~V} 50 \mathrm{~Hz}$ power system network. During the PSpice test, a load of a $2 \Omega$ impedance was chosen. According to the design capability of the compensation system, a lagging power factor of 0.707 of the above load can be corrected to unity. If the power factor is lower than 0.707 , a partial power factor improvement can be expected. Firstly, the compensation system was tested at the rated resistive load $(2 \Omega)$. Fig. 9 shows the performance results of this test. Fig. 9a shows that the adaptive current controller approached steady performance at $t=200 \mathrm{~ms}$. This is deduced from the error signal $K_{I} \Delta I$ which attained a zero value at this time and sustained it. Fig. 9a shows that the current drawn from the AC source $i_{A C}$ approached zero at $t=160 \mathrm{~ms}$. Consequently, it can be said that the steady state performance in this figure started at $t=200 \mathrm{~ms}$. The voltage $v_{C X}$ attained a value of $+5 \mathrm{~V}$, which corresponded to the zero firing angle of the TCR. Therefore, the TCR was running at its maximum inductive current rating, which cancelled the capacitive current generated by the third harmonic filter.

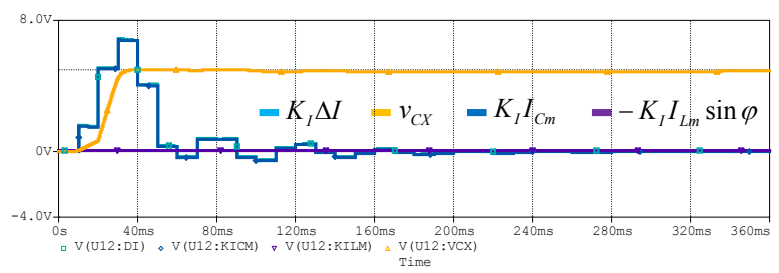

(a)
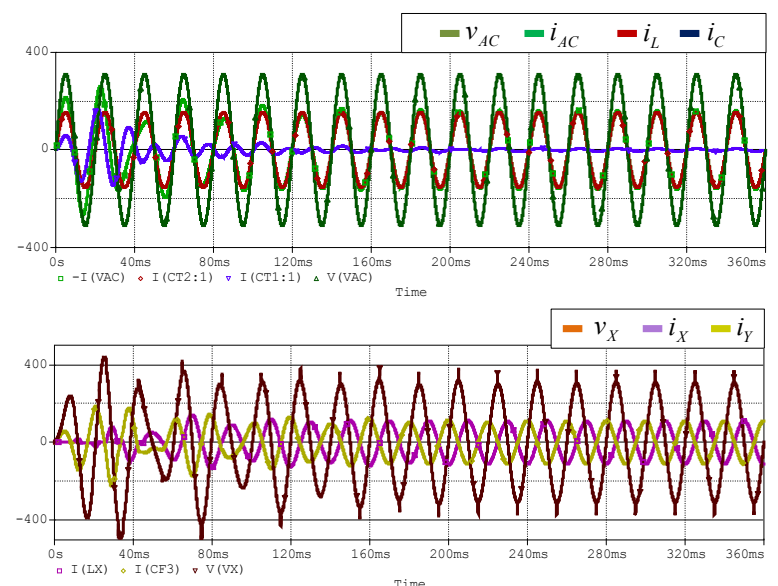

(b)

Fig. 9. Transient and steady state performance during rated resistive load: (a) current controller, (b) the whole compensator.

Fig. 10, Fig. 11, and Fig. 12 show the transient and steady state performance results of the automatic power factor correction system during the compensation of inductive rated loads at $0.9,0.8$, and 0.707 lagging power factors, respectively. In Fig. 10(a), the error signal of the current controller settled to the zero value at $t=200 \mathrm{~ms}$. At this time, the voltage $v_{X}$ is about $2.5 \mathrm{~V}$. This value of $v_{X}$ corresponds to a firing angle of 0.98 radians $\left(56^{0}\right)$. According to Equation (25), the zero error signal means that the compensator capacitive current and the load reactive current components are equal in magnitude and out of phase by $180^{\circ}$. This situation corresponds to unity power factor correction.

In Fig. 11(a), the current error signal settled to the zero value before $t=200 \mathrm{~ms}$ while $v_{X}$ settled to the steady state value at the same time. In this figure, $v_{X}$ is slightly less than $2 \mathrm{~V}$. This value of $v_{X}$ corresponds to a firing angle of slightly less than $\pi / 4$.

In Fig. 12(a), the current error signal settled to the zero value before $t=200 \mathrm{~ms}$ while $v_{X}$ settled to the zero value at the same time. This value of $v_{X}$ corresponds to a firing angle of $\pi / 2$, which in turn corresponds to the zero TCR current. Fig. 12(b) shows the zero reactive current absorbed by the TCR.

\section{B. steady State Performance}

The steady state performance started at about $t=200 \mathrm{~ms}$ after the first plug in of the compensator to the power system network. However, for better evaluation of the harmonic contents, the steady state performance tests were carried out beyond $t=300 \mathrm{~ms}$. Fig. 13 shows the steady state performance 


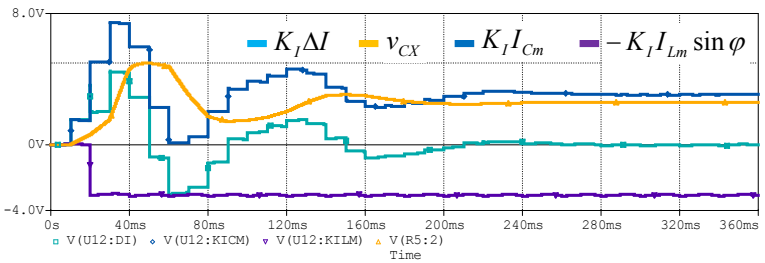

(a)

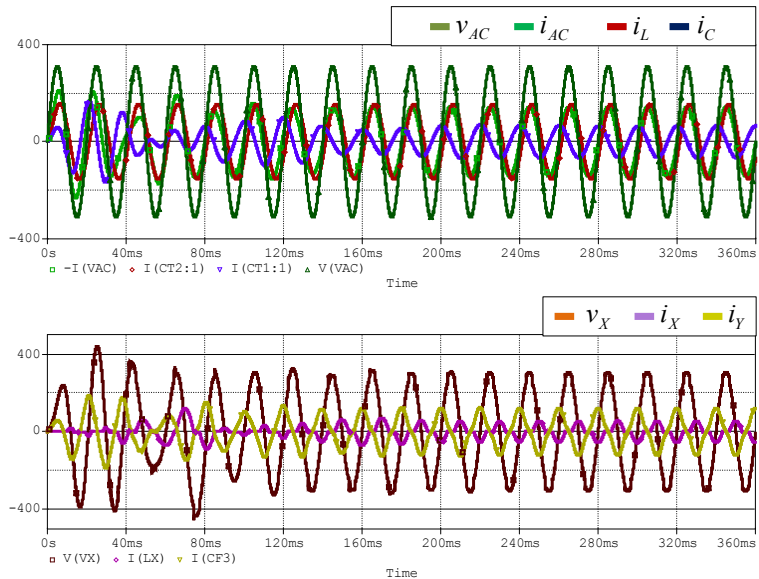

(b)

Fig. 10. Transient and steady state performance results during rated load at 0.9 lagging power factor: (a) current controller, (b) the whole compensator.

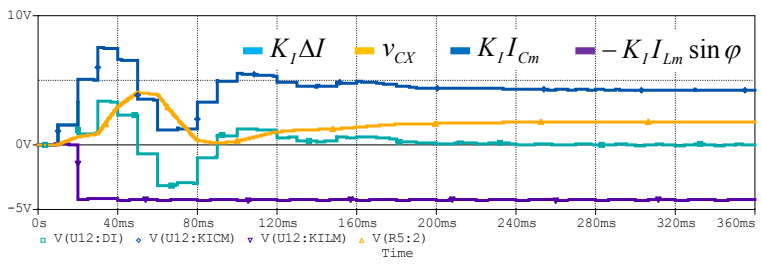

(a)

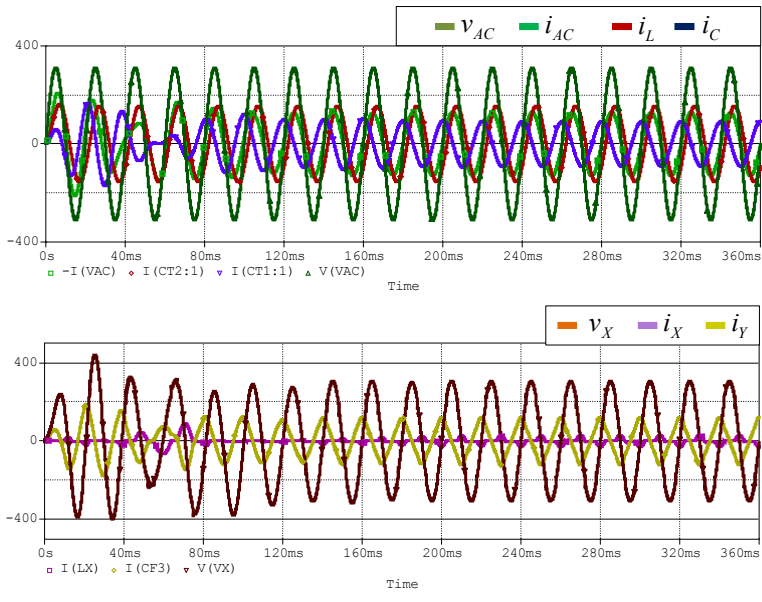

(b)

Fig. 11. Transient and steady state performance results during rated load at 0.8 lagging power factor: (a) current controller, (b) the whole compensator.

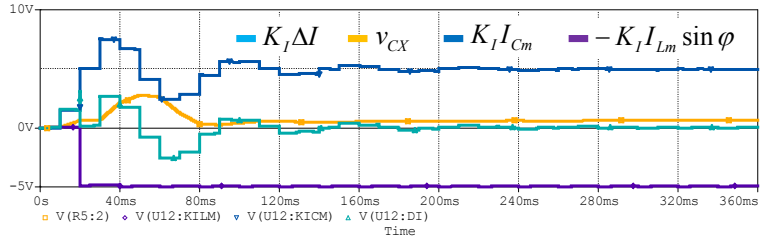

(a)

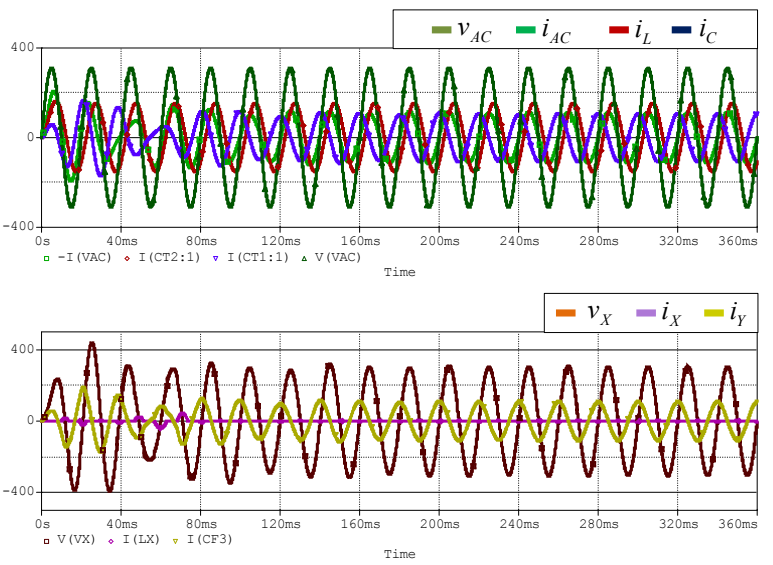

(b)

Fig. 12. Transient and steady state performance results during rated load at 0.707 lagging power factor: (a) current controller, (b) the whole compensator.

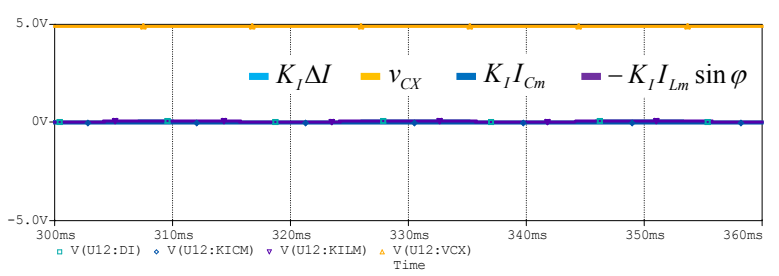

Fig. 13. Steady state performance results of the adaptive current controller during rated resistive load.

of the adaptive current controller during a resistive load.

Fig. 14(a), Fig. 14(b), and Fig. 14(c) show the steady state performance results of the adaptive current controller corresponding to the loading conditions specified in Fig. 10(a), Fig. 11(a), and Fig. 12(a), respectively. Fig. 13 and Fig. 14 show that the voltage signals $K_{I} I_{C m}$ and $K_{I} I_{L m} \sin \varphi$ are equal in magnitude and having different signs. Therefore, the error signal $\Delta I$ is zero. In addition, these figures show a constant $v_{X}$ during steady state performance. This guaranties a fixed firing angle.

Fig. 15, Fig. 16, Fig. 17, and Fig. 18 show the steady state performance of the compensation process corresponding to the loading conditions specified in Fig. 9(b), Fig. 10(b), Fig. 11(b), and Fig. 12(b), respectively. Fig. 15 corresponds to the rated resistive load. Since the reactive current component is zero, the compensator current should also be zero according 


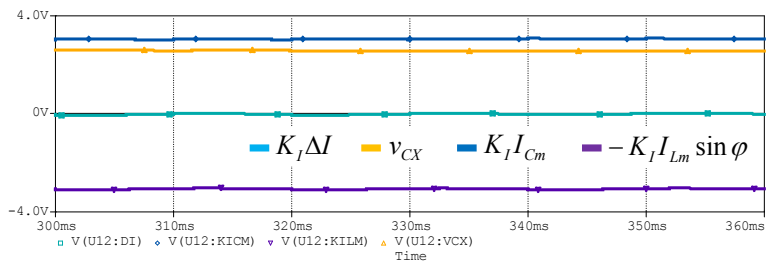

(a)

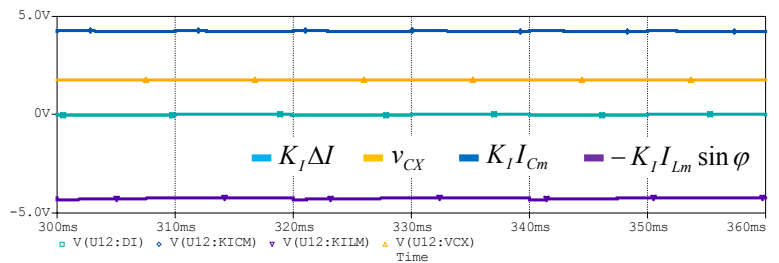

(b)

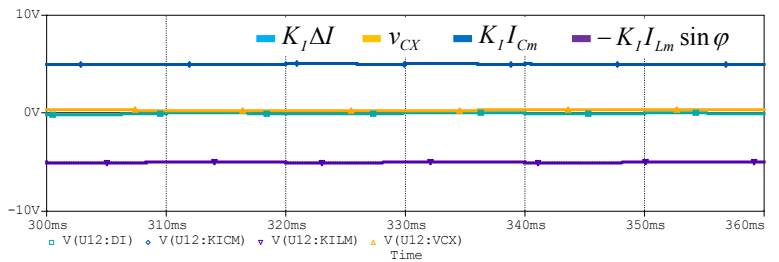

(c)

Fig. 14. Steady state performance of the current controller during rated loads at lagging power factor of: (a) 0.9 , (b) 0.8 , (c) 0.707 .

to Equation (25). The figure shows that the AC source $i_{A C}$ and the load current $i_{L}$ are coinciding with each other.

Fig. 16 corresponds to a rated inductive load at a 0.9 lagging power factor. The reactive current component of this current is $68 \mathrm{~A}$ (peak value). Therefore, the compensator should generate a reactive current of $68 \mathrm{~A}$ (peak value) in order to achieve a unity power factor correction to $i_{A C}$. The unity power factor correction is obvious in this figure.

Fig. 17 and Fig. 18 correspond to rated inductive loads at 0.8 and 0.707 lagging power factors, respectively. The reactive current components of these currents are $93 \mathrm{~A}$ and 110A (peak values), respectively. The compensator was able to compensate the above load reactive current components and the compensation processes resulted in a unity power factor correction to $i_{A C}$ as shown in these two figures.

In Fig. 15 to Fig. 18, no sign of current harmonics beyond the fundamental component are noticeable on the compensator current frequency spectrum $F\left(i_{C}\right)$, the AC source current frequency spectrum $F\left(i_{A C}\right)$, or the load current frequency spectrum $F\left(i_{L}\right)$. Consequently, this automatic power factor correction system is harmonic-free.

In Fig. 15, the instantaneous TCR current $i_{X}$ and the third harmonic filter current $i_{Y}$ are pure sinusoidal, equal in magnitude, and out of phase by $180^{\circ}$. Therefore, they cancel each other out and result in almost zero compensating current $i_{C}$. Consequently, the linearly and continuously controlled capacitive compensator used in this compensation system and represented by the harmonic-suppressed TCR is a pure
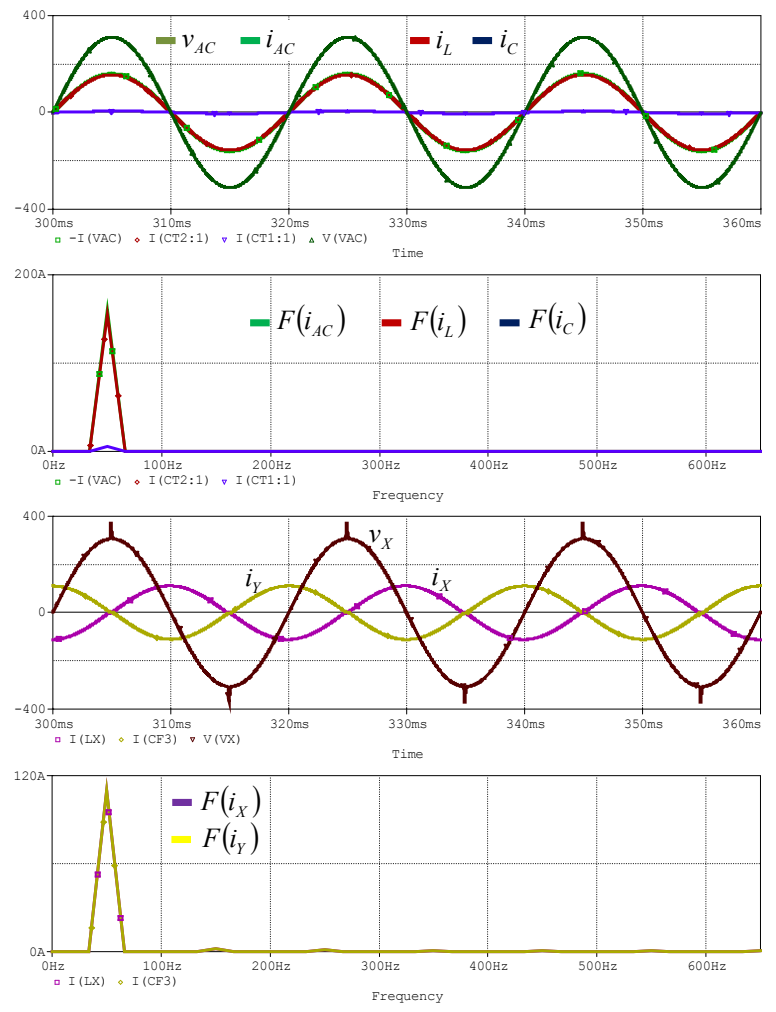

Fig. 15. The compensator steady state performance during rated resistive load.
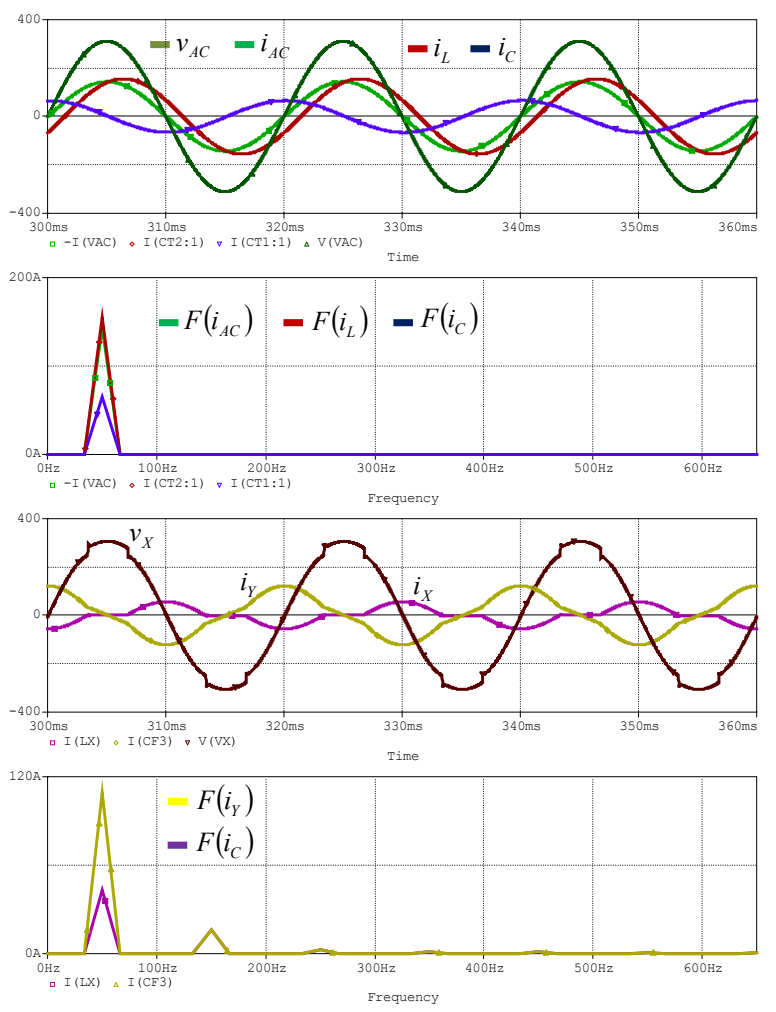

Fig. 16. The compensator steady state performance during rated inductive load at 0.9 lagging power factor. 

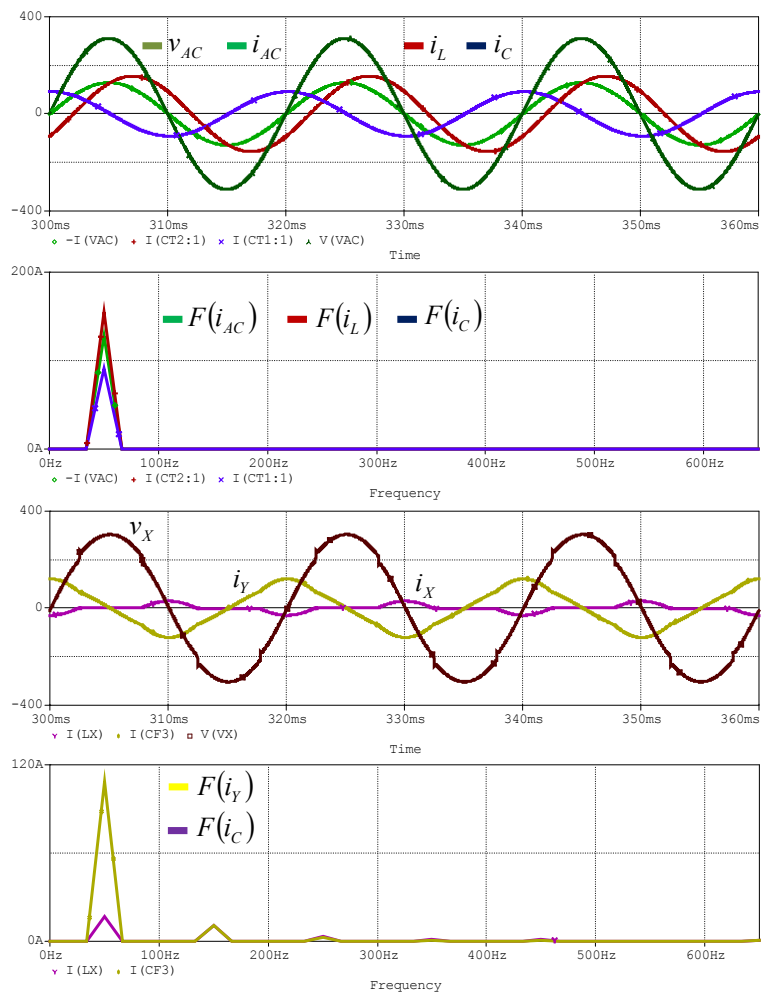

Fig. 17. The compensator steady state performance during rated inductive load at 0.8 lagging power factor.
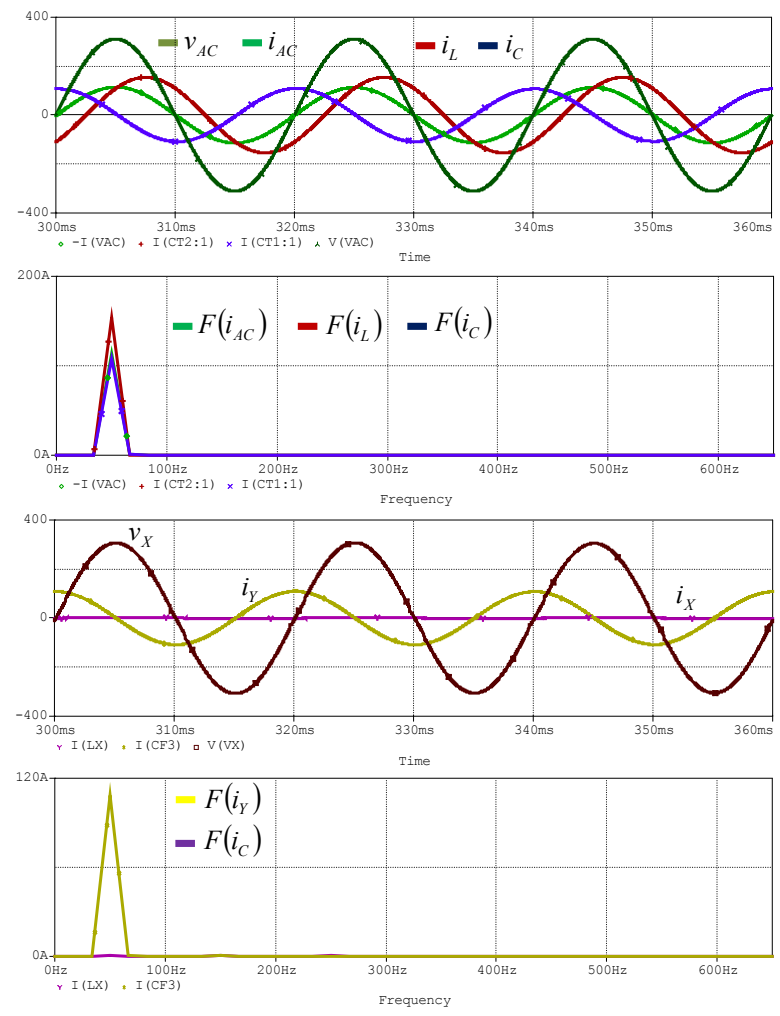

Fig. 18. The compensator steady state performance during rated inductive load at 0.707 lagging power factor. reactive device having negligible no load operating losses.

The TCR current frequency spectrum $F\left(i_{X}\right)$ and the third harmonic filter current frequency spectrum $F\left(i_{Y}\right)$ coincide with each other in Fig. 15 to Fig. 18. The fact that they coincide verifies that this compensation system is harmonic-free.

The above applied tests show that the new adaptive current controller approaches its steady state performance within a time of about $200 \mathrm{~ms}$. This time is very small when compared to those achieved by the phase shift current controller in [2], the microprocessor based power factor controller in [4], the hysteresis current controller depicted in [5], and the SVC current controller with a Fuzzy ranking system in [7]. For instance, the steady state performance time for the hysteresis current controller [5] is about one second. This is approximately five times the transient time of the new current controller adopted in this paper.

The frequency spectrums of the steady state current of the harmonic-suppressed TCR demonstrate its efficiency as a linear harmonic-free capacitive static VAR compensator. It reveals excellent harmonic cancellation when compared to traditional static VAR compensators such as the power factor compensator and harmonic suppresser in [2]. In addition, it exhibits competitive compensation and harmonic cancellation efficiencies when compared to the advanced static compensators depicted in [6], [11], [13], [22].

\section{CONCLUSIONS}

There are three types of control schemes used to govern the susceptances of static VAR compensators. The first scheme is dependent on direct computations of the VAR demands to specify the firing triggering signals of the switching devices of static VAR compensators. This type of control is referred to as open loop control. The second type depends on feedback control to govern the current of the static VAR compensator. However, this type of control requires undistorted compensating currents in order to settle accurately and rapidly to the steady state operation. The third controlling scheme mixes these two approaches of control. Traditionally, TCR control is usually realized by the first control scheme through look up tables, programmable controlling schemes, direct analogue computations, and analogue simulation of the TCR current fundamental. This is because the TCR current waveform is not sinusoidal. In this paper, an adaptive closed loop controlling strategy for a TCR is presented. This is done because all of the harmonic current components released by the TCR are not permitted to be injected into the AC source side. Consequently, the harmonic-suppressed TCR based capacitive static VAR compensator becomes a harmonic-free pure reactive device that can be controlled using closed loop strategies. The perfect 
unity power factor correction handled by the proposed automatic power factor correction system validates its design methodology and reveals it potency in energy saving for generation stations and the reduction of transmission losses.

\section{REFERENCES}

[1] L. Gyugyi, "Power electronics in electric utilities: static Var compensators," in Proc. the IEEE, Vol. 76, No. 4, pp. 483-494, Apr. 1988.

[2] L. T. Moran, P. D. Ziogas, and G. Joos, "Analysis and design of a novel 3- $\phi$ solid-state power factor compensator and harmonic suppressor system," IEEE Trans. Ind. Appl., Vol. 25, No. 4, pp. 609-619, Jul./Aug. 1989.

[3] D. Raonic and D. Cyganski, "Power factor compensation at busses with slightly distorted voltage due to random harmonics," IEEE Trans. Power Del., Vol. 4, No. 1, pp. 502-507, Jan. 1989.

[4] H. M. Al-Bolok, M. E. Masoud, and M. M. Mahmoud, "A microprocessor-based adaptive power factor corrector for nonlinear loads," IEEE Trans. Ind. Electron., Vol. 37, No. 1, pp. 77-81, Feb. 1990.

[5] S. Hirve, K. Chatterjee, B. G. Fernandes, M. Imayavaramban, and S. Drawi, "PLL-less active power filter based on one-cycle control for compensating unbalanced loads in three-phase four-wire system," IEEE Trans. Power Del., Vol. 22, No. 4, pp. 2457-2465, Oct. 2007.

[6] B. Singh, P. Jayaprakash, T. R. Somayajulu, and D. P. Kothari, "Reduced rating VSC with a zig-zag transformer for current compensation in a three-phase four-wire distribution system," IEEE Trans. Power Del., Vol. 24, No. 1, pp. 249-259, Jan. 2009.

[7] D. B. Kulkarni and G. R. Udupi, "ANN-based SVC switching at distribution level for minimal-injected harmonics," IEEE Trans. Power Del., Vol. 25, No. 3, pp. 1978-1985, Jul. 2010.

[8] Y. Xu, L. M. Tolbert, J. D. Kuek, and D. T. Rizy, "Voltage and current unbalance compensation using a static VAR compensator," IET Power Electron., Vol. 3, No. 6, pp. 977-988, Oct. 2010

[9] IEEE PES Harmonic Working Group, "Characteristics and modeling of harmonic sources-power electronic devices," IEEE Trans. Power Del., Vol. 16, No. 4, pp. 791-800, Oct. 2001.

[10] J. E. R. Alves,Jr., L. A. S. Pilotto, and E. H. Watanabe, "Thyristor-controlled reactors nonlinear and linear dynamic analytical models," IEEE Trans. Power Del., Vol. 23, No. 1, pp. 338-346, Jan. 2008.

[11] A. Luo, Zhikang Shuai, Wenji Zhu, and Z. John Shen, "Combined system for harmonic suppression and reactive power compensation," IEEE Trans. Ind. Electron., Vol. 56, No. 2, pp. 418-428, Feb. 2009.

[12] B. T. Ooi, M. Kazerani, R. Marceau, Z. Wolanski, F. D. Galiana, D. McGillis, and G. Joos, "Mid-point siting of FACTS devices in transmission lines," IEEE Trans. Power Del., Vol. 12, No. 4, pp. 1717-1722, Oct. 1997.

[13] K. N. Strivastava and S.C Strivastava, "Elimination of dynamic bifurcation and chaos in power systems using FACTS devices," IEEE Trans. Circuits and Syst. I
Fundam. Theory Appl., Vol. 45, No. 1, pp. 72-78, Jan. 1998.

[14] P. Pourbeik and M.J. Gibbard, "Simultaneous coordination of power system stabilizers and FACTS device stabilizers in a multimachine power system for enhancing dynamic performance," IEEE Trans. Power Syst., Vol. 13, No. 2, pp. 473-479, May 1998.

[15] W. L. Tan and Y. Wang, "Effects of FACTS controller line compensation on power system stability," IEEE Power Eng. Rev., pp. 55-56, Aug. 1998.

[16] M. H. Haque, "Evaluation of first swing stability of a large power system with various FACTS devices," IEEE Trans. Power Syst., Vol. 23, No. 3, pp. 1144-1151, Aug. 2008.

[17] A. K. Chakravorti and A.E. Emanuel. "A current regulated switched capacitor static volt ampere reactive compensator," IEEE Trans. Ind. Appl., Vol. 30, No. 4, pp. 986-997, Jul./Aug. 1994.

[18] S. Nandi, P. Biswas, V. N. Nandakumar, and R. K. Hedge, "Two novel schemes suitable for static switching of three-phase delta-connected capacitor banks with minimum surge current," IEEE Trans. Ind. Appl., Vol. 33, No. 5, pp. 1348-1354, Sep./Oct. 1997.

[19] J. Dixon, L. Moran, J. Rodriguez, and R. Domke, "Reactive power compensation technologies: state-of-art review," in Proc. The IEEE, Vol. 93, No. 12, pp 2144-2164, Dec. 2005.

[20] R. Gupta, A. Ghosh, and A Joshi, "Switching characterization of cascaded multilevel-inverter-controlled systems," IEEE Trans. Ind. Electron., Vol. 55, No. 3, pp. 1047-1058, Mar. 2008.

[21] J. Wen and K. M. Smedley, "Synthesis of multilevel converters based on single and or three-phase converter building blocks," IEEE Trans. Power Electron., Vol. 23, No. 3, pp. 1247-1256, May 2008.

[22] A. Hamadi, S. Rahmani, and K. Al, "A Hybrid passive filter configuration for VAR control and harmonic compensation," IEEE Trans. Ind. Electron., Vol. 57, No. 7, pp. 2419-2434, Jul. 2010.

[23] Y. Sumi, Y. Hanunoto, T. Hasegawa, M. Yano, K. Ikeda, and T. Matsuura, "New Static VAR control using forced-commutated inverter," IEEE Trans. Power App. S yst., Vol. PAS-100, No. 9, pp. 4216-4224, Sep. 1981.

[24] Y. Ye, M. Kazerani, and V. H. Quintana, "Current-source converter based STATCOM: modeling and control," IEEE Trans. Power Del., Vol. 20, No. 2, pp. 795- 800, Apr. 2005.

[25] J. A. Barrena, L. Marroyo, M. A. R. Vidal, and J. R. T. Apraiz, "Individual voltage balancing strategy for PWM cascaded H-bridge converter-based STATCOM," IEEE Trans. Ind. Electron., Vol. 55, No. 1, pp. 21-29, Jan. 2008.

[26] Q. Song and W. Liu, "Control of a cascade STATCOM with star configuration under unbalanced conditions," IEEE Trans. Power Electron., Vol. 24, No. 1, pp. 45-57, Jan. 2009.

[27] H. P. Mohammadi and M.T. Bina, "A transformerless medium-voltage STATCOM topology based on extended modular multilevel converters," IEEE Trans. Power Electron., Vol. 26, No. 5, pp. 1534-1545, May 2011. 


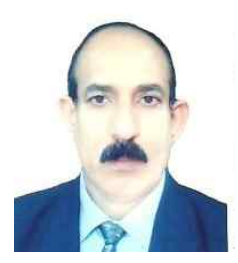

Abdulkareem Mokif Obais was born in Iraq, in 1960. He received his B.S. and M.S. degrees in Electrical Engineering from the University of Baghdad, Baghdad, Iraq, in 1982 and 1987, respectively, and his Ph.D. degree in Electrical Engineering from the Universiti Tewnaga Nasional, Kajang, Malaysia, in 2013. He joined Alkufa University, Kufa, Iraq, as an Assistant Lecturer, in 1988, and then joined Babylon University, Babylon, Iraq, in 1991. He was promoted to Lecturer and Assistant Professor, in 1996 and 2000, respectively. In 2008, he was promoted to Professor in the Department of Electrical Engineering, College of Engineering, Babylon University. He has supervised and examined a number of postgraduate students. He has published many papers in Iraqi academic and international Journals.

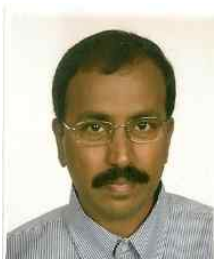

Jagadeesh Pasupuleti was born in Vadamalapeta, India. He received his B.S. degree in Electrical and Electronics Engineering from Acharya Nagarjuna University, Guntur, India, in 1986, and his M.S. and Ph.D. degrees in Electrical and Electronics Engineering with a specialization in power system operation and control from Sri Venkateswara University, Tirupati, India, in 1988 and 2002, respectively. He has published a number of papers in international conference proceedings and international journals in the fields of power system operation and control as well as renewable energy. His current research interests include power system operation and control, applications of power electronics and renewable energy. Dr. Pasupuleti is a Senior Member of IEEE, and a Member of IET and ISTE. 